\title{
Evaluating Wind Energy Potential in Gorgan-Iran Using Two Methods of Weibull Distribution Function
}

\author{
D. Babayania, M. Khaleghib, S. Tashakorc, M. Hashemi-Tilehnoee a,* \\ a Young Researchers and Elite Club, Aliabad Katoul Branch, Islamic Azad University, Aliabad Katoul, Iran \\ ${ }^{b}$ Department of Mechanical Engineering, Sirjan University of Technology, Kerman, Iran \\ ${ }^{c}$ Department of Mechanical Engineering, Shiraz Branch, Islamic Azad University, Shiraz, Iran
}

\begin{abstract}
In this study, wind energy characteristics of the, a city in northeast of Iran, measured at $10 \mathrm{~m}$ height in 2014 . The Gorgan airport one hour recorded data extrapolated to $50 \mathrm{~m}$ height. The data have been statistically analyzed hourly, daily, monthly, seasonally and annually to determine the wind power potential. Weibull distribution function has been used to determine the wind power density and then the potential energy. Standard deviation method (SDM) and power density method (PDM) are the methods used to calculate the scaling and shaping parameters of the Weibull distribution function. The annual mean wind power calculated by the standard deviation method and the power density method is $38.98 \mathrm{w} / \mathrm{m}^{2}$ and $41.32 \mathrm{w} / \mathrm{m}^{2}$, respectively. By comparing the results concluded that the power density method is a better method than the standard deviation method. In addition, Gorgan wind energy potentiality categorized into class 1 . So is unsuitable to utilize large wind energy turbine.
\end{abstract}

Keywords: Wind energy, Standard deviation method, Power density method, Weibull distribution function, Gorgan, Iran

Article History: Received November 21, 2015; Received in revised form January 15, 2016; Accepted February 10, 2016; Available online How to Cite This Article: Babayani, D., Khaleghi, M., Tashakor, S., and Hashemi-Tilehnoee.,M. (2016) Evaluating wind energy potential in GorganIran using two methods of Weibull distribution function. Int. Journal of Renewable Energy Development, 5(1), 43-48.

http://dx.doi.org/10.14710/ijred.5.1.43-48

\section{Introduction}

Renewable energy sources like wind energy are estimated to provide about \%18 of the world's final energy needs in many countries as well as Iran (Mostafaeipour and Abarghooei 2008). Many studies have regarded the determination of wind energy potential in various areas of Iran such as Manjil in Gilan province (Mostafaeipour and Abarghooei 2008), Tehran, the capital city of Iran (Keyhani et al. 2010), five cities in Semnan province (Mirhosseini et al. 2011), Shahrbabak in Kerman province (Mostafaeipour et al. 2011), Zarrineh in Kurdistan province (Mohammadi and Mostafaeipour 2013a), Aligoodarz in the west of Iran (Mohammadi and Mostafaeipour 2013b), Kerman in Iran (Mostafaeipour 2013), Zahedan in Iran (Mostafaeipour et al. 2014), Binalood in Iran (Mostafaeipour et al. 2013), Hormozgan province (Nedaei 2014), Abadan airport in Khuzestan province (Nedaei 2012a), Chalus in Mazandaran province (Nedaei 2012b), port of Chabahar in southeast of Iran (Biglari et al. 2013), Mah-shahr station in Iran (Nedaei et al. 2014), Two northeast provinces; North and South
Khorasan (Saeidi et al. 2011), Baladeh and Nur in Mazandaran Province (Janbaz Ghobadi et al. 2011) Firouzkouh in Iran (Emami and Behbahani-Nia 2012), the province of Sistan and Baluchestan (Razavieh et al. 2014), three free economic and industrial zones, Chabahar, Kish and Salafchegan (Mohammadi et al. 2014) and Golestan Province in Iran (Babayani, Khaleghi and Hashemi-Tilehnoee, 2016). The present study, focused on energy evaluation of the capital of Golestan province. It is coordinated at $36^{\circ} 50^{\prime} 19^{\prime \prime} \mathrm{N}$ and $54^{\circ} 26^{\prime} 05^{\prime \prime} \mathrm{E}$ in the northeast of the Iran. Fig. 1 shows the location of the Gorgan in the map of Golestan province.

This province suffers from the lack of energy resources. A portion of required gas imported from neighbor country and only one power plant was built to produce electrical power. So, if the wind energy evaluations show a good characteristic it can be used as an auxiliary renewable energy source. In this study, two methods of the Weibull distribution function used for wind energy potential evaluation of Gorgan. Weibull distribution function usually known as the most

\footnotetext{
*corresponding author

email: mehdi.hashemi.t@gmail.com
} 
Citation: Babayani, D., Khaleghi, M., Tashakor, S., and Hashemi-Tilehnoee.,M. (2016) Evaluating wind energy potential in Gorgan-Iran using two methods of Weibull distribution function. Int. Journal of Renewable Energy Development, 5(1),43-48, doi : 10.14710/ijred.5.1.43-48

$\mathrm{P}$ a g e $\mid 44$

qualified function due to its simplicity and acceptable accuracy level for wind speed data analysis (Mostafaeipour et al. 2011; Mohammadi and Mostafaeipour, 2013a).

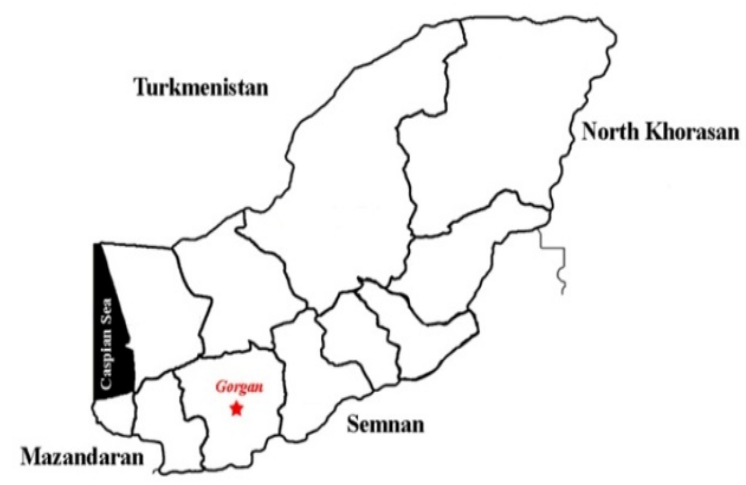

Fig. 1: Map of Golestan province

Several methods have been proposed to estimate the Weibull parameters. Some of these methods are graphical method, moment method, standard deviation method, maximum likelihood method, energy pattern factor method, and power density method. In this study, standard deviation method and power density method are used to estimate the Weibull function parameters.

\section{Materials and Methods}

In order to use wind energy, it is important to determine the power density in the intended area. The most accurate method to calculate wind power potential is based on measured values that record at the meteorological station. The second method to asses wind power potential is using a probability distribution function. In this study, wind energy potential for Gorgan airport calculated with two different methods which applied to Weibull probability distribution function. Power density method and standard deviation method used for obtaining shape and scale parameters. Measurement periods for synoptic station are hourly and the height of wind speed measurement is $10 \mathrm{~m}$. However the wind data extrapolated to the height of $50 \mathrm{~m}$ above the ground. Using the power law formula, wind speed data can be calculated as follows (Mostafaeipour et al. 2013):

$$
\frac{v}{v_{o}}=\left(\frac{h}{h_{o}}\right)^{\alpha}
$$

Where $v_{\mathrm{o}}$ is the known measured wind speed at the original height ho, and $v$ is the calculated wind speed at height $h$. Also the power law component " $\alpha$ " as a function of velocity and height is usually expressed as (Nedaei et al. 2014):

$$
\alpha=\frac{0.37-0.088 \ln \left(v_{o}\right)}{1-0.088 \ln \left(h_{o}\right)}
$$

For this research " $\alpha$ " is taken 0.143 . The measured wind power, which shows how much energy is available at the intended site, is proportional to cube of wind speed and can be computed using the following equation (Razavieh et al. 2014, Mohammadi et al. 2014):

$$
P=\frac{1}{2} \rho v^{3}\left(W / m^{2}\right)
$$

The mean wind power density for any specified periods of time can be calculated as follows (Mohammadi et al. 2014):

$\bar{P}=\frac{1}{2 n} \rho \sum_{i=1}^{n} v^{3}=\frac{1}{2 n} \rho \overline{v^{3}}\left(W / m^{2}\right)$

$\mathrm{n}$ is the number of all data that was used in the specified period of time. $\rho$ is the density of air at sea level with a mean temperature of $15{ }^{\circ} \mathrm{C}$ and a pressure of $1 \mathrm{~atm}$ $\left(1.225 \mathrm{~kg} / \mathrm{m}^{3}\right)$ and $\mathrm{v}$ is the mean wind speed $(\mathrm{m} / \mathrm{s})$. Then the corrected monthly air density $\rho\left(\mathrm{kg} / \mathrm{m}^{3}\right)$ is calculated as follows (Nedaei et al. 2014):

$$
\rho=\frac{\bar{p}}{R_{d} \bar{T}}
$$

where $\bar{T}$ is average monthly air temperature in Kelvin $(\mathrm{K}), p$ is the average monthly air pressure in Pascal $(\mathrm{Pa})$, and Rd is gas constant for dry air, which its value is 287 $\mathrm{J} / \mathrm{kg} \mathrm{K}$. Once the wind power is estimated, the wind energy for a specific period of time can be calculated (Nedaei et al. 2014):

$$
\bar{E}=\bar{P} T
$$

\subsection{Weibull distribution function}

The Weibull probability density function (PDF) is given as (Mostafaeipour et al. 2011; Mohammadi and Mostafaeipour, 2013a):

$$
f w(v)=\frac{k}{c}\left(\frac{v}{c}\right)^{k-1} \exp \left(-\left(\frac{v}{c}\right)^{k}\right)
$$

Also, the cumulative density function (CDF) of the Weibull distribution is expressed as:

$$
F_{w}(v)=1-\exp \left(-\left(\frac{v}{c}\right)^{k}\right),(k>0, v>0, c>1)
$$


Where, $\mathrm{k}$ is dimensionless shape parameter and $\mathrm{c}$ is the scale parameter $(\mathrm{m} / \mathrm{s})$ respectively, and $\mathrm{v}$ is the wind speed $(\mathrm{m} / \mathrm{s})$.

\subsubsection{Power density method}

To obtain shape factor and scale factor through this method, first, the energy pattern factor is computed. The energy pattern factor usage is for turbine aerodynamic design and defined as a ratio between mean of cubic wind speed to cube of mean wind speed. In this method, Weibull factors can be obtained as follows (Mostafaeipour et al. 2011; Mohammadi and Mostafaeipour, 2013a):

$$
\begin{aligned}
& E_{p f}=\frac{\frac{1}{n} \sum_{i=1}^{n} v_{i}^{3}}{\left(\frac{1}{n} \sum_{i=1}^{n} v_{i}\right)^{3}}=\frac{v^{3}}{\bar{v}^{3}}=\frac{\Gamma\left(1+\frac{3}{k}\right)}{\Gamma^{3}\left(1+\frac{3}{k}\right)} \\
& k=1+\frac{3.69}{\left(E_{p f}\right)^{2}} \\
& c=1+\frac{\bar{v}}{\Gamma\left(1+\frac{1}{k}\right)}
\end{aligned}
$$

Where $\bar{v}$ and $\sigma$ are mean wind speed and standard deviation of wind speed for specified periods of time, respectively, and can be calculated as follows (Mostafaeipour et al. 2011; Mohammadi and Mostafaeipour, 2013a):

$$
\begin{aligned}
& \bar{v}=\frac{1}{n} \sum_{i=1}^{n} v_{i} \\
& \sigma=\left[\left(\frac{1}{n-1} \sum_{i=1}^{n}\left(v_{i}-\bar{v}\right)^{2}\right)\right]^{0.5}
\end{aligned}
$$

And also $\Gamma(\mathrm{x})$ is the gamma function and is defined as follows:

$$
\Gamma(x)=\int_{0}^{\infty} \exp (-u) u^{x-1} d x
$$

\subsubsection{Standard deviation method}

In this method, Weibull " $\mathrm{k}$ " factors can be obtained as follows (Mostafaeipour et al. 2011; Mohammadi and Mostafaeipour, 2013a):

$$
k=\left(\frac{\sigma}{\bar{v}}\right)^{-1.086}
$$

The calculation method for scale factor is same as the power density method and can be estimated from equation (11).

The wind power per unit area based on Weibull probability density function can be expressed as (Mostafaeipour et al. 2011; Mohammadi and Mostafaeipour, 2013a):

$$
P=\frac{1}{2} \rho \int_{0}^{\infty} v^{3} f_{w}(v) d v=\frac{1}{2} \rho c^{3} \Gamma\left(1+\frac{1}{3}\right)
$$

The coefficient of variation (COV) demonstrating mutability of wind speeds and is the ratio between mean standard deviation to mean wind speed. The coefficient of variation (COV) is defined in percent and can be calculated by following formula (Mostafaeipour et al. 2011; Mohammadi and Mostafaeipour, 2013a):

$$
\operatorname{COV}(\%)=\left(\frac{\sigma}{\bar{v}}\right) x 100
$$

We introduced two methods to estimate Weibull factors for finding performance of each method to calculate mean wind power. To find the best method, relative percentage error (RPE) defined as (Mostafaeipour et al. 2011; Mohammadi and Mostafaeipour, 2013a):

$$
R P E=\left(\frac{P_{w}-P_{m d}}{P_{m d}}\right) x 100
$$

Where $P_{w}$ is measured wind power and $P_{m d}$ calculate power by Weibull distribution, respectively.

\subsection{Turbulence intensity}

Turbulence in the wind is caused by dissipation of the wind's kinetic energy into thermal energy via the creation and destruction of progressively smaller eddies. The most basic measure of turbulence is the turbulence intensity. The length of this time period is normally no more than an hour, and by convention in wind energy engineering it is usually equal to $10 \mathrm{~min}$. Turbulence intensity changes with the mean wind speed, surface roughness, atmospheric stability, and topographic features (Mirhosseini, Sharifi, and Sedaghat 2011). It is defined by the ratio of the standard deviation of the wind speed to the mean:

$$
T I=\left(\frac{\sigma_{v}}{\bar{v}}\right)
$$


Citation: Babayani, D., Khaleghi, M., Tashakor, S., and Hashemi-Tilehnoee.,M. (2016) Evaluating wind energy potential in Gorgan-Iran using two methods of Weibull distribution function. Int. Journal of Renewable Energy Development, 5(1),43-48, doi : 10.14710/ijred.5.1.43-48

P a g e 46

\subsection{Maximum energy and most probable wind speed}

In the study of wind energy feasibility, the nominal wind speed is used to determine the maximum energy in all over the year, as a speed that produces maximum energy along the year. This speed is one of the significant characters in turbine designing and is given by (Mostafaeipour et al. 2011; Mohammadi and Mostafaeipour, 2013a):

$U_{m e}=c\left(\frac{k+2}{k}\right)^{\frac{1}{k}}$

The most probable wind speed $\left(U_{m p}\right)$ shows the most frequent wind speed for a given wind probability distribution (Mostafaeipour et al. 2011; Mohammadi and Mostafaeipour, 2013a):

$U_{m p}=c\left(1-\frac{1}{k}\right)^{\frac{1}{k}}$

\section{Result and discussion}

In this study, wind speed data of Gorgan-airport have been statistically analyzed. Besides the mean wind speed and the coefficient of variation (COV), the mean wind power calculated by a Weibull distribution function with two different strategies at $50 \mathrm{~m}$ and compared with measurement data. The daily variations of wind speed in $50 \mathrm{~m}$ above the ground are plotted in Fig. 2 for a month.

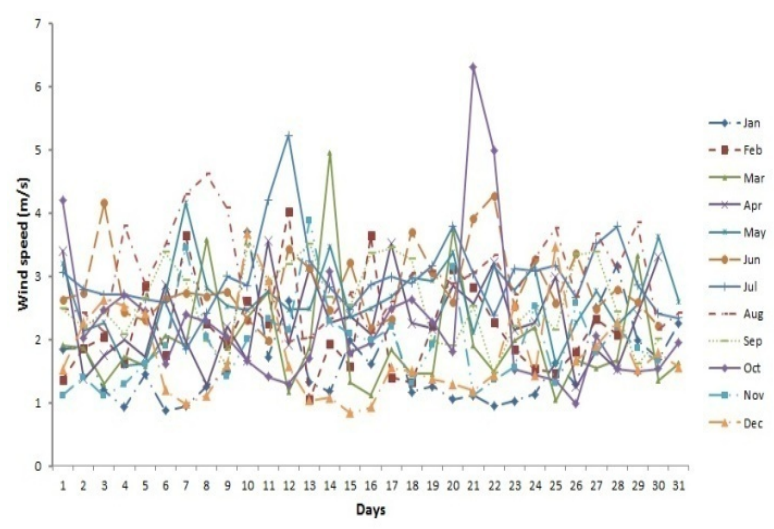

Figure 2. Daily wind speed during a month

According to the Figure 2, Gorgan had strongest mean values of wind speed in July. The highest value of the wind speed was in October 21 and low of them occurred in December 15. Table 1 indicates monthly, seasonally and annually average wind speed, standard deviation $(\sigma)$, and coefficient of variation (COV). Also, the calculated shape factor and scale factor by the standard deviation method and power density method are shown in Table 1.

The calculated shape factor by standard deviation method varied from 1.32 to 2.33 . Using power density method, the shape factor calculated from 1.25 to 2.30. The scale factor obtained from standard deviation method and power density method were in the range of $2.28-4.24 \mathrm{~m} / \mathrm{s}$ and $2.26-4.24 \mathrm{~m} / \mathrm{s}$, respectively. Fig. 3 shows the monthly, seasonally and annually mean wind power based on measured data, standard deviation method and power density method.

Table 1

Monthly, seasonal and yearly wind energy statistical parameters

\begin{tabular}{|c|c|c|c|c|c|c|c|}
\hline \multirow{2}{*}{$\begin{array}{l}\text { Month } \\
\text { Season }\end{array}$} & \multicolumn{5}{|c|}{ SDM } & \multicolumn{2}{|l|}{ PDM } \\
\hline & $\begin{array}{l}\bar{v} \\
(\mathrm{~m} / \mathrm{s})\end{array}$ & $\sigma$ & $\begin{array}{l}\text { COV } \\
(\%)\end{array}$ & $\mathrm{k}(-)$ & $\begin{array}{l}\mathrm{c} \\
(\mathrm{m} / \mathrm{s})\end{array}$ & $\mathrm{k}(-)$ & $\begin{array}{l}\mathrm{c} \\
(\mathrm{m} / \mathrm{s})\end{array}$ \\
\hline January & 2.05 & 1.36 & 66.29 & 1.56 & 2.28 & 1.47 & 2.27 \\
\hline February & 2.78 & 1.78 & 64.10 & 1.62 & 3.11 & 1.51 & 3.09 \\
\hline March & 2.48 & 1.75 & 70.50 & 1.46 & 2.74 & 1.35 & 2.70 \\
\hline April & 3.34 & 1.81 & 54.13 & 1.95 & 3.77 & 1.89 & 3.77 \\
\hline May & 3.65 & 2.03 & 55.52 & 1.89 & 4.11 & 1.86 & 4.11 \\
\hline June & 3.76 & 2.03 & 54.01 & 1.95 & 4.24 & 1.92 & 4.24 \\
\hline July & 3.76 & 2.03 & 54.01 & 1.95 & 4.24 & 1.92 & 4.24 \\
\hline August & 3.74 & 1.71 & 45.83 & 2.33 & 4.22 & 2.30 & 4.22 \\
\hline September & 3.28 & 1.67 & 50.95 & 2.08 & 3.71 & 2.07 & 3.71 \\
\hline October & 2.82 & 2.18 & 77.30 & 1.32 & 3.06 & 1.25 & 3.03 \\
\hline November & 2.45 & 1.50 & 61.48 & 1.70 & 2.74 & 1.53 & 2.72 \\
\hline December & 2.23 & 1.53 & 68.62 & 1.51 & 2.47 & 1.42 & 2.45 \\
\hline January & 2.05 & 1.36 & 66.29 & 1.56 & 2.28 & 1.47 & 2.27 \\
\hline Spring & 2.44 & 1.67 & 68.39 & 1.51 & 2.70 & 1.40 & 2.67 \\
\hline Summer & 3.53 & 1.95 & 55.33 & 1.90 & 3.98 & 1.86 & 3.97 \\
\hline Autumn & 3.55 & 1.84 & 52.00 & 2.03 & 4.00 & 2.00 & 4.00 \\
\hline Winter & 2.47 & 1.73 & 70.05 & 1.47 & 2.73 & 1.35 & 2.69 \\
\hline $\begin{array}{l}\text { Warm } \\
\text { seasons }\end{array}$ & 2.98 & 1.89 & 63.53 & 1.64 & 3.33 & 1.57 & 3.32 \\
\hline $\begin{array}{l}\text { Cold } \\
\text { seasons }\end{array}$ & 3.01 & 1.87 & 62.03 & 1.68 & 3.37 & 1.60 & 3.36 \\
\hline Annual & 3.00 & 1.88 & 62.78 & 1.66 & 3.35 & 1.59 & 3.34 \\
\hline
\end{tabular}

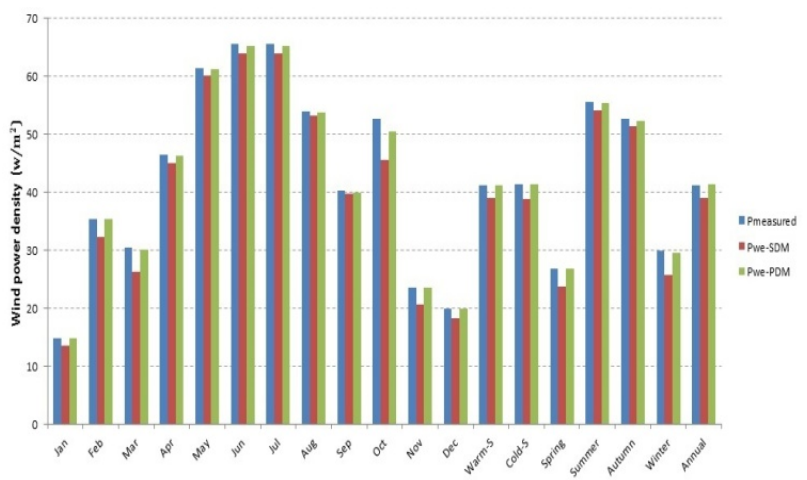

Figure 3. Measured and calculated monthly, seasonal and annual mean wind power $\left(\mathrm{w} / \mathrm{m}^{2}\right)$ 
The highest values of mean wind power by measuring data, standard deviation method and power density method are $65.52 \mathrm{~W} / \mathrm{m}^{2}, 63.92 \mathrm{~W} / \mathrm{m}^{2}$, and $65.16 \mathrm{~W} / \mathrm{m}^{2}$, respectively. In addition, the lowest values of mean wind power by measuring data, standard deviation method and power density method are $14.825 \mathrm{~W} / \mathrm{m}^{2}$, $13.530 \mathrm{~W} / \mathrm{m}^{2}$, and $14.826 \mathrm{~W} / \mathrm{m}^{2}$, respectively. By using the pacific northwest laboratory (PNL) wind power classification scheme unfortunately at $50 \mathrm{~m}$ height and in all of months the wind power falls in class $1(\mathrm{P} \leq 100$ $\mathrm{W} / \mathrm{m}^{2}$ ) which indicates unsuitable condition. Fig. 4 shows the relative percentage errors of the mean wind power which calculated by the standard deviation method and the power density method.

It is obvious from the RPE radar chart that power density method has lower error rather than standard deviation method. Fig. 5 shows monthly, seasonally, annual Maximum energy $\left(U_{m p}\right)$ and most probable wind speed $\left(U_{m e}\right)$ which calculated by the two methods, SDM and PDM methods.

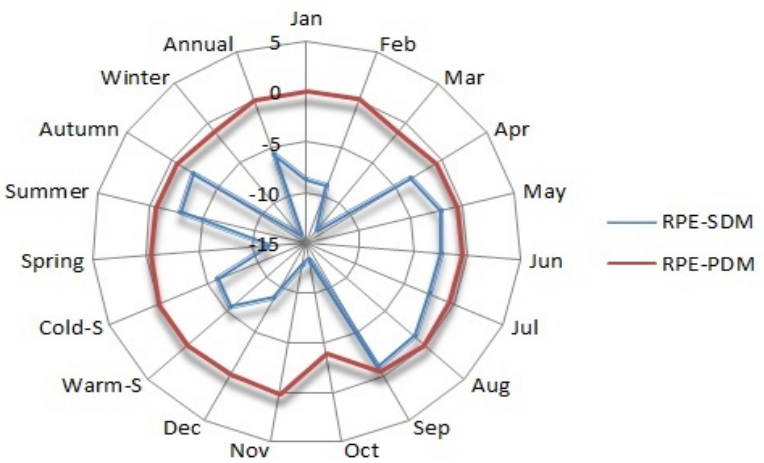

Fig. 4: RPE radar chart of PDM and SDM methods (\%)

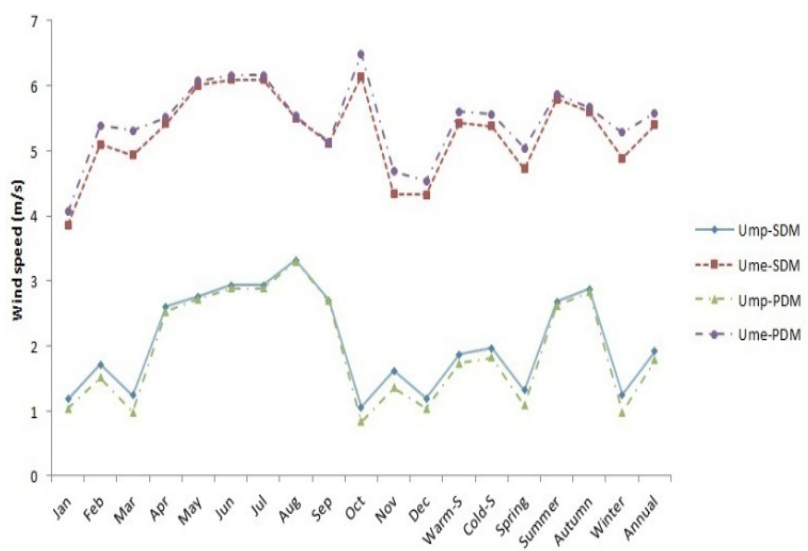

Figure 5. calculated Ume and Ump by SDM and PDM methods

The results of two methods are almost close to each other. Mean of Ume and Ump by the standard deviation method are $5.27 \mathrm{~m} / \mathrm{s}$ and $2.0623 \mathrm{~m} / \mathrm{s}$ respectively, and these values were calculated by the power density method as $5.45 \mathrm{~m} / \mathrm{s}$ and $1.93 \mathrm{~m} / \mathrm{s}$, respectively. In addition to statistical analysis, wind turbulence intensity is measured and shown in Fig. 6.

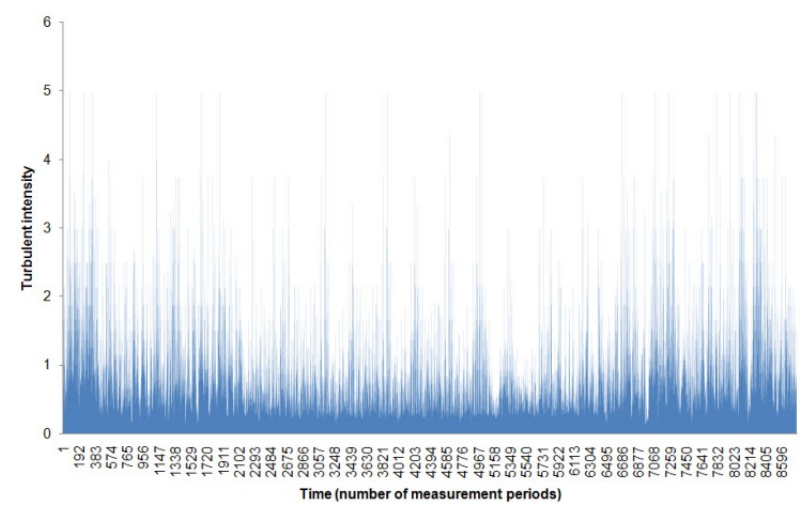

Figure 6. Measured time history of wind speed at $50 \mathrm{~m}$ height.

According to Fig. 6, maximum of turbulence intensity is about 5.09 and the average of it is 0.97. The corresponding wind data and best fits to a twoparameter Weibull distribution using the standard deviation method and the power density method at a height of $50 \mathrm{~m}$ for Gorgan airport is shown in Figure 7.

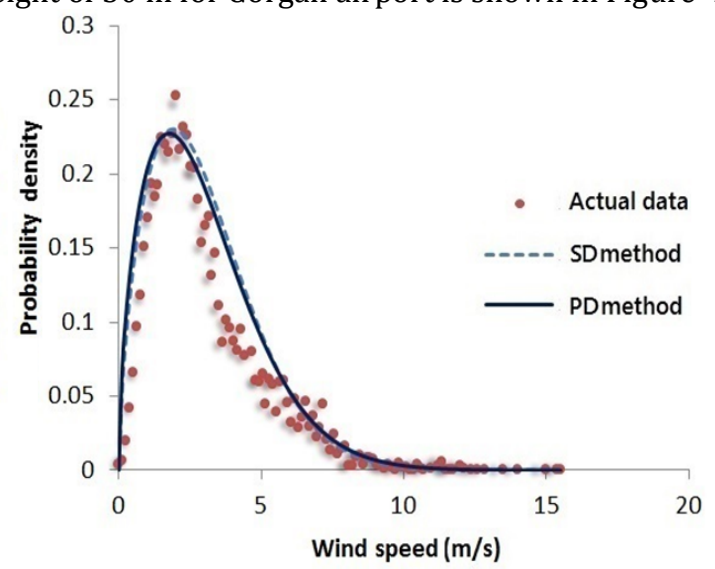

(a)

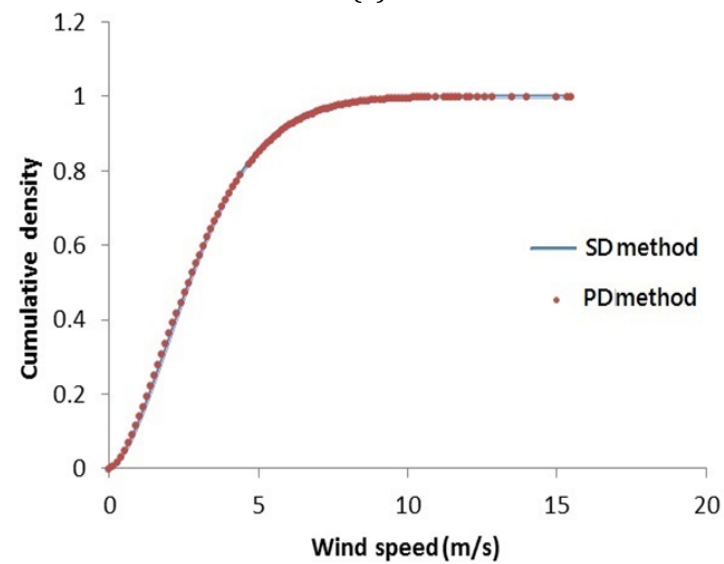

(b)

Figure 7. Weibull distribution a) Measured and calculated Wind probability density at $50 \mathrm{~m} \mathrm{~b}$ ) Calculated cumulative density at $50 \mathrm{~m}$ 
Citation: Babayani, D., Khaleghi, M., Tashakor, S., and Hashemi-Tilehnoee.,M. (2016) Evaluating wind energy potential in Gorgan-Iran using two methods of Weibull distribution function. Int. Journal of Renewable Energy Development, 5(1),43-48, doi : 10.14710/ijred.5.1.43-48

P a g e $\mid 48$

It is obvious from Fig. 7-(a) that the probability density at $50 \mathrm{~m}$ calculated from Weibull distribution has no extended shape and its amplitude is low. According to Fig. 7-(b) cumulative distribution curve of the studied wind speeds, It can be noted that, for example, the wind speed of Gorgan at $50 \mathrm{~m}$ height is greater than $4 \mathrm{~m} / \mathrm{s}$ for about $60 \%$ of the time in the year. The $4 \mathrm{~m} / \mathrm{s}$ wind speed limit is important, because it is the cut-in speed of many commercial turbines. The wind direction is of paramount importance for the possibility assessment of using wind energy and plays a significant role in the optimal positioning of a wind farm in an intended area. Fig. 8 illustrates the monthly wind direction at $50 \mathrm{~m}$ height. Limitation of wind direction has a significant preference for wind powerhouse.

From Figure 8, the annual mean wind direction is about 185. Changes in wind direction are due to the general circulation of the atmosphere, again on an annual basis (seasonal) to the mesoscale. The seasonal changes of prevailing wind direction could be as little as $30^{\circ}$ in trade wind regions to as high as $180^{\circ}$ in temperate regions

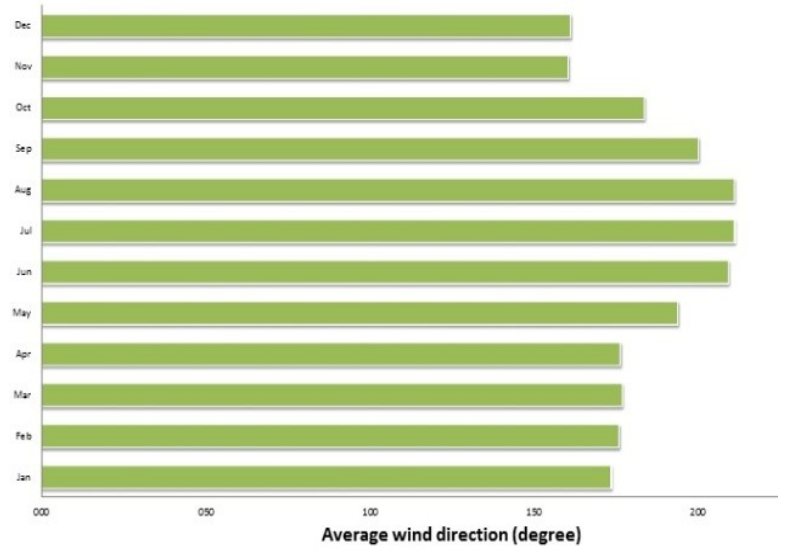

Figure 8. Monthly mean wind direction

\section{Conclusion}

This paper presented short-term one hour period wind speed data which measured $10 \mathrm{~m}$ and calculated $50 \mathrm{~m}$ height of Gorgan. The most important outcomes of the study can be summarized as follows:

- Wind speeds are modeled using the Weibull probability function with an acceptable RPE values. The Weibull parameters $\mathrm{k}$ (dimensionless) and $c(\mathrm{~m} / \mathrm{s})$ are shown in Table 1 . The results of the standard deviation method and power density method are nearly similar with a low RPE.

- The results of different month wind speed and Weibull distribution shows that Gorgan is either a poor location to utilize the wind energy or it is not suitable for construction small wind turbines.
- Results show that the power density method is better than standard deviation method in estimating wind energy potential.

\section{References}

Biglari, M., Assareh, E., Nedaei, M. \& Poultangari, I. (2013) An initial evaluation of wind resource in the Port of Chabahar in South East of Iran. Glob J Sci Eng Technol, 2(14), 142-148.

Emami, N., \& Behbahani-Nia A., (2012) The Statistical Evaluation of Wind Speed and Power Density in the Firouzkouh Region in Iran. Energy Sources A, 34, 1076-1083.

Babayani, D., Khaleghi, M, \& Hashemi-Tilehnoee, M., (2016) Assessment of wind energy potential in Golestan-Iran. Int. J. Renew, Energy. Dev, Inpress.

Janbaz Ghobadi, G., Gholizadeh, B. \& Soltani, B. (2011) Statistical evaluation of wind speed and energy potential for the construction of a power plant in Baladeh, Nur, Northern Iran. International Journal of the Physical Sciences, 6(19), 4621-4628.

Keyhani, A., Ghasemi-Varnamkhasti, M., Khanali, M. \& Abbaszadeh, R. (2010) An assessment of wind energy potential as a power generation source in the capital of Iran, Tehran. Energy, 35, 188201.

Mirhosseini, M., Sharifi, F. \& Sedaghat, A. (2011) Assessing the wind energy potential locations in province of Semnan in Iran. J Renew Sustain Energy Rev, 15, 449-459.

Mohammadi, K., Mostafaeipour, A., \& Sabzpooshani, M. (2014) Assessment of solar and wind energy potentials for three free economic and industrial zones of Iran. Energy, 67, 117-128.

Mohammadi, K., \& Mostafaeipour, A. (2013a) Using different methods for comprehensive study of wind turbine utilization in Zarrineh, Iran. Energy Convers Manage, 65, 463-470.

Mohammadi, K., \& Mostafaeipour, A. (2013b) Economic feasibility of developing wind turbines in Aligoodarz, Iran. Energy Convers Manage, 76, 645-653.

Mostafaeipour, A., \& Abarghooei, H. (2008) Harnessing wind energy at Manjil area located in north of Iran. J Renew Sustain Energy Rev, 12, 1758-1766.

Mostafaeipour, A., Sedaghat, A., Dehghan-Niri, A.A., \& Kalantar, V. (2011) Wind energy feasibility study for city of Shahrbabak in Iran. J Renew Sustain Energy Rev, 15,2545-2556.

Mostafaeipour, A., (2013) Economic evaluation of small wind turbine utilization in Kerman, Iran. Energy Convers Manage, 73, 214-225.

Mostafaeipour, A., Jadidi, M., Mohammadi, K. \& Sedaghat, A. (2014) An analysis of wind energy potential and economic evaluation in Zahedan, Iran. Renew Sustain Energy Rev, 30, 641-650.

Mostafaeipour, A., Sedagh, A., Ghalishooyan, M., Dinpashoh, Y., Mirhosseini, M., Sefid, M. \& Pour-Rezaei, M. (2013) Evaluation of wind energy potential as a power generation source for electricity production in Binalood, Iran. Renew Energy, 52,222-229.

Nedaei, M., (2014) Wind resource assessment in Hormozgan province in Iran. Int J Sustain Energy, 33,650-694.

Nedaei, M., (2012a) Wind resource assessment in Abadan airport in Iran. Int J Renew Energy Dev, 1,87-97.

Nedaei, M., (2012b) Wind energy potential assessment in Chalus County in Iran. Int J Renew Energy Res, 2, 338-347.

Nedaei, M., Assareh, E. \& Biglari, M. (2014) An extensive evaluation of wind resource using new methods and strategies for development and utilizing wind power in Mah-shahr station in Iran. Energy Conversion and Management, 81,475-503.

Razavieh, A., Sedaghat, A., Ayodele, R., \& Mostafaeipour, A., (2014) Worldwide wind energy status and the characteristics of wind energy in Iran, case study: the province of Sistan and Baluchestan. International Journal of Sustainable Energy, 1-21 (Article in Press).

Saeidi, D., Mirhosseini, M., Sedaghat, A. \& Mostafaeipour, A. (2011) Feasibility study of wind energy potential in two provinces of Iran: North and South Khorasan. Renewable and Sustainable Energy Reviews, 15, 3558-3569. 